\title{
Sol-gel synthesized mesoporous anatase titanium dioxide nanoparticles for dye sensitized solar cell (DSSC) applications
}

\author{
R GOVINDARAJ ${ }^{1, *}$, M SENTHIL PANDIAN ${ }^{1}$, P RAMASAMY $^{1}$ and SUMITA MUKHOPADHYAY ${ }^{2}$ \\ ${ }^{1}$ SSN Research Centre, SSN College of Engineering, Chennai 603 110, Tamilnadu, India \\ ${ }^{2}$ Centre of Excellence for Green Energy and Sensor Systems, Indian Institute of Engineering Science and Technology, \\ Howrah, West Bengal 711 103, India
}

MS received 13 September 2014; revised 14 October 2014

\begin{abstract}
Hierarchically structured titanium dioxide nanoparticles were successfully synthesized by the sol-gel method. The synthesized nanoparticles were subjected to powder X-ray diffraction, UV-Vis DRS spectroscopy, Brunauer-Emmett-Teller method, Barrett-Joyner-Halenda analysis, field emission scanning electron microscopy, high-resolution transmission electron microscopy and energy-dispersive X-ray analysis. The powder X-ray diffraction pattern shows that the obtained particles are of anatase phase with good crystallite nature. The nitrogen adsorption and desorption isotherms show that the prepared material has surface area of $31.71 \mathrm{~m}^{2} \mathrm{~g}^{-1}$ and the pore size distribution analysis shows the average pore diameters of mesoporous $\mathrm{TiO}_{2}$ nanostructures to be 7.1 and $9.3 \mathrm{~nm}$. The UV-Vis DRS spectrum shows that the $\mathrm{TiO}_{2}$ nanoparticles are having absorption in the ultraviolet region. The optical band gap of the nanoparticles is $3.2 \mathrm{eV}$. The morphological studies show the morphology of the particles as spherical in shape. The elemental compositions of $\mathrm{TiO}_{2}$ nanoparticles were confirmed by energy-dispersive $\mathrm{X}$-ray spectrum analysis. The conversion efficiency of the solar cell was $3.415 \%$ with open-circuit voltage $\left(V_{0 c}\right)$, short-circuit current $\left(J_{\text {sc }}\right)$ and fill factor (FF) of $0.607 \mathrm{~V}, 13.206 \mathrm{~mA} \mathrm{~cm}^{-2}$ and $42.56 \%$, respectively.
\end{abstract}

Keywords. Semiconductors; sol-gel; solar cells; $\mathrm{TiO}_{2}$.

\section{Introduction}

Fujishima and Honda ${ }^{1}$ first discovered the phenomenon of photocatalytic splitting of water over a $\mathrm{TiO}_{2}$ electrode under ultraviolet light in 1972. The effective utilization of clean, safe and abundant solar energy through the $\mathrm{TiO}_{2}$ photocatalysis provides promising solutions to the energy crisis and serious environmental challenges. $\mathrm{TiO}_{2}$ has been widely used commercially in pigments, ${ }^{2}$ sunscreens, ${ }^{3,4}$ paints, ${ }^{5}$ toothpaste, ${ }^{6}$ etc. Mesoporous materials ${ }^{7,8}$ have a wide range of applications, including their important role in photoelectrochemical cells, photocatalysts and sensors.

Dye sensitized solar cells (DSSCs) as alternatives to traditional silicon-based solar cell devices have attracted widespread attention due to their clean and pollution free nature, easy fabrication and powerful harvesting efficiency. ${ }^{9}$ One of the key elements in DSSC is the mesoporous $\mathrm{TiO}_{2}$ photoanode, which transfers the charge carriers from the sensitizer (dye) to the fluorine-doped tin oxide (FTO) electrode and concurrently allows the electrolytes (redox couples) to diffuse to the anchored dyes. Typically, nanoparticles are used for the fabrication of the mesoporous $\mathrm{TiO}_{2}$ layers on the FTO to obtain high surface areas and generate nanopored structures. ${ }^{10,11}$ In general, upon decreasing the size of $\mathrm{TiO}_{2}$ nanoparticles, the surface area of the fabricated nanoporous

\footnotetext{
*Author for correspondence (isrogovindaraj@gmail.com)
}

$\mathrm{TiO}_{2}$ film is increased, and thus more dye molecules can be adsorbed. However, the average pore size is decreased simultaneously, and more defect sites and grain boundaries can be generated in the fabricated $\mathrm{TiO}_{2}$ film. These defects will affect efficiency of DSSC. Kim et $a l^{12}$ reported that nanoporous spherical structures will provide both high adsorption of dye molecules and efficient electrolyte diffusion. In addition, the spherical $\mathrm{TiO}_{2}$ structures offer a considerable scattering effect in the long-wavelength region. Generally, $\mathrm{TiO}_{2}$ contains three different phases (anatase, rutile and brookite). Among them anatase and rutile phases are having several applications. The optical band gap of $\mathrm{TiO}_{2}$ nanostructures with anatase phase is $3.2 \mathrm{eV}$, whereas for the rutile it is $3.0 \mathrm{eV}{ }^{13}$ The anatase conduction band is $0.2 \mathrm{eV}$ more negative than that of rutile if the same redox material is employed. This will cause more open-circuit voltage in DSSC than rutile phase.

In this work, we have synthesized hierarchically structured anatase $\mathrm{TiO}_{2}$ nanoparticles with moderate surface area by the sol-gel method. The resulting materials have the spherical morphology via aggregation of anatase phase particles. The obtained products were characterized by powder X-ray diffraction (PXRD), UV-Vis DRS spectroscopy, BrunauerEmmett-Teller (BET) method, Barrett-Joyner-Halenda (BJH) analysis, field emission scanning electron microscopy (FESEM) and high-resolution transmission electron microscopy (HRTEM). 


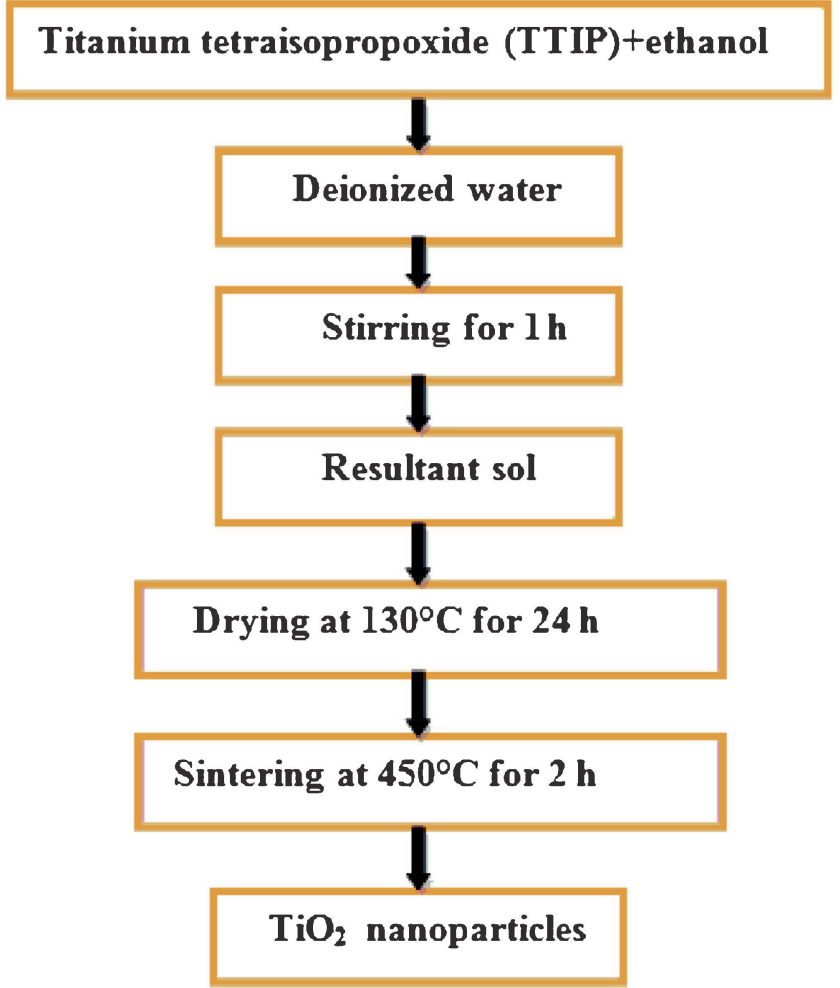

Figure 1. Hydrolysis and polycondensation reaction mechanism of sol-gel process.

\section{Experiment}

\subsection{Synthesis procedure}

The synthesized product was obtained from titanium (IV) isopropoxide, $\geq 97 \%$ (Sigma Aldrich) dissolved in ethanol (Merck) and deionized water was added to the solution in molar ratio of $\mathrm{Ti}: \mathrm{H}_{2} \mathrm{O}=1: 4$. The mixed solution was vigorously stirred for $1 \mathrm{~h}$ in order to form sols. After aging for a day, the sols were transformed into gel form. The hydrolysis and condensation mechanism is given in figure 1 . The obtained gels were dried at $120^{\circ} \mathrm{C}$ for $24 \mathrm{~h}$ to remove the water and organic materials. After that, the dried gel was sintered at $450^{\circ} \mathrm{C}$ for $2 \mathrm{~h}$ in homemade high temperature programmable furnace. Finally the pure $\mathrm{TiO}_{2}$ nanoparticles were obtained. Figure 2 shows the synthesis procedure of $\mathrm{TiO}_{2}$ nanoparticles given in flow chart.

\subsection{Fabrication of DSSCs}

The electrodes were prepared as follows: $1 \mathrm{~g}$ of prepared $\mathrm{TiO}_{2}$ powder was mixed with $0.1 \mathrm{ml}$ of acetylacetone and ground mechanically. During vigorous stirring, $5 \mathrm{ml}$ of mixture of water and ethanol $(1: 1 \mathrm{vol} \%)$ was added and $0.4 \mathrm{ml}$ of polyoxethylene (10) octylphenyl ether (Triton $\mathrm{X}-100$ ) was added with the above solution to form a paste. The obtained colloidal paste was coated on the FTO (sheet resistance, $8 \Omega / \square$ ) substrate by the doctor-blade technique. After coating, the resulting film was sintered at $500^{\circ} \mathrm{C}$ for $1 \mathrm{~h}$. The sintered electrodes were soaked in $0.3 \mathrm{mM}$ of cis-bis(isothiocyanato)bis(2,2'-bipyridyl-4,4'dicarboxylato ruthenium(II) (known as N3) dye in an ethanol solution. The counter electrode was prepared by the docterblade technique using Platisol T/SP (Solaronix SA) precursor and thermally decomposed at $400^{\circ} \mathrm{C}$ for $30 \mathrm{~min}$. Finally both electrodes are sandwiched together to form a cell. The small amount of electrolyte (Iodolyte AN-50) was injected into cell.

\section{Results and discussions}

\subsection{PXRD}

The phase composition and the crystallite size of the prepared $\mathrm{TiO}_{2}$ nanoparticles were evaluated by PXRD analysis. Figure 3 shows the PXRD pattern of $\mathrm{TiO}_{2}$ nanoparticles obtained by sintering at $450^{\circ} \mathrm{C}$ which shows preferred orientation corresponding to the plane (101). All the diffraction peaks in the diffraction patterns can be indexed as anatase phase of $\mathrm{TiO}_{2}$ nanoparticles and the diffraction pattern was in good agreement with JCPDS files \# 21-1272. ${ }^{14}$ Crystallite size was calculated by Debye-Scherrer's formula given by

$$
D=K \lambda / \beta \cos \theta,
$$

where $D$ is the crystallite size, $\lambda$ the wavelength of the $\mathrm{X}$ ray radiation $(\lambda=0.15406 \mathrm{~nm})$ for $\mathrm{CuK} \alpha, K$ the constant $(K=0.89)$ and $\beta$ the full-width at half-maximum of (101) plane. The crystallite size of $\mathrm{TiO}_{2}$ nanoparticles is $17 \mathrm{~nm}$.

\subsection{UV-Vis DRS spectroscopy}

Optical properties were studied by UV-Vis DRS spectroscopy. Figure 4a shows the optical absorption spectra of $\mathrm{TiO}_{2}$ nanoparticles. The absorption edge of $\mathrm{TiO}_{2}$ nanoparticles is $396 \mathrm{~nm}$. The optical absorption coefficient $(\alpha)$ of a semiconductor is expressed by the following equation:

$$
\alpha=A\left(h v-E_{\mathrm{g}}\right)^{n} / h v,
$$

Here $\alpha$ is the absorption coefficient, $E_{\mathrm{g}}$ the band gap, $A$ is a constant depending on the transition probability, $n$ depends on the nature of the transition, i.e., allowed direct, allowed indirect, forbidden direct and forbidden indirect. In our case, for an indirect band gap, the value of $n$ is $1 / 2 .{ }^{15}$ The variation of $(\alpha h v)^{1 / 2}$ with photon energy is shown in figure $4 \mathrm{~b}$. The band gap is found to be $3.2 \mathrm{eV}$.

\subsection{BET and BJH analysis}

The specific surface area and porosity of the mesoporous anatase $\mathrm{TiO}_{2}$ were evaluated by using the nitrogen adsorption and desorption isotherms after sintering at $450^{\circ} \mathrm{C}$ as 


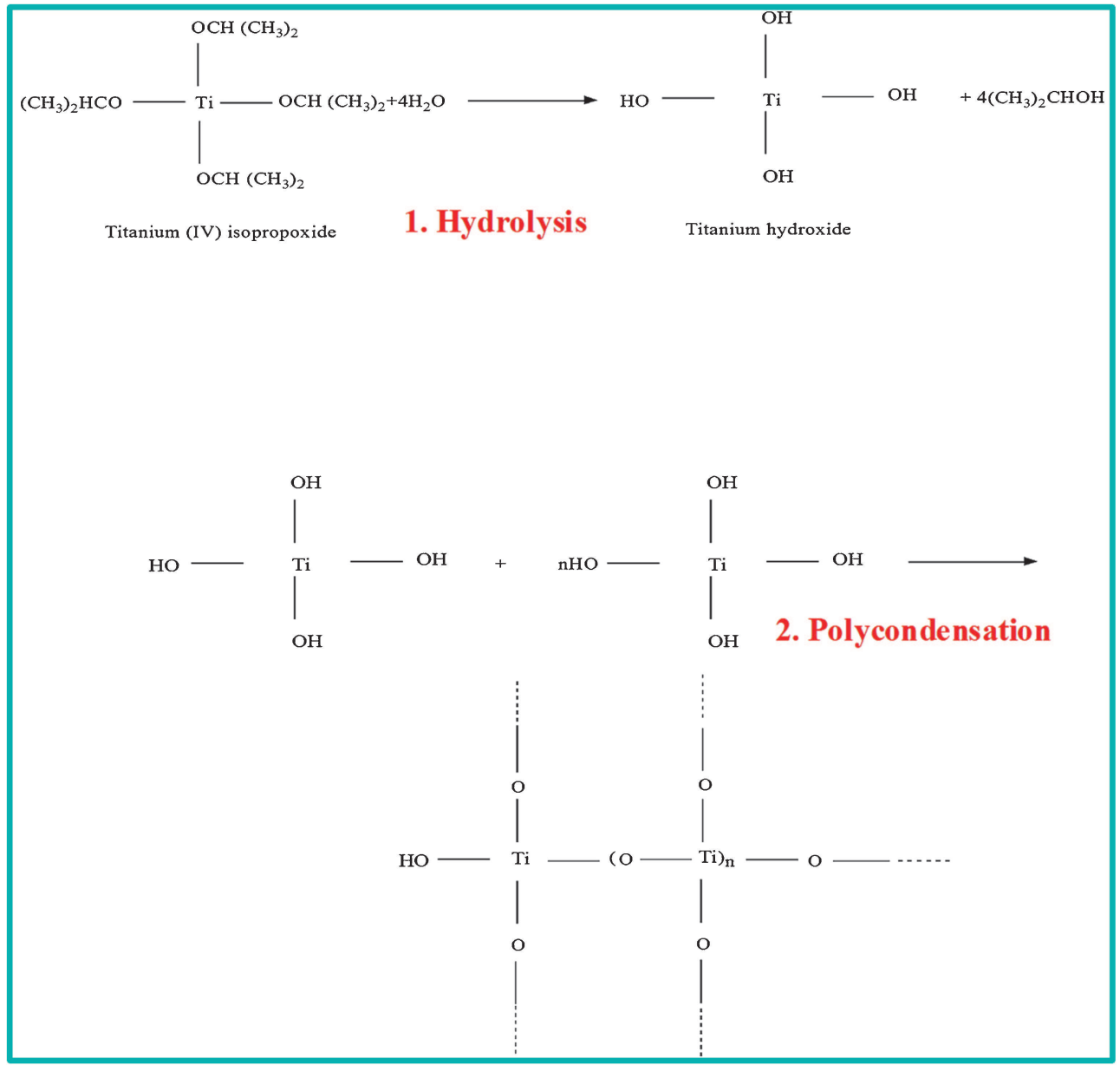

Figure 2. Flow chart: preparation methodology of spherical shape $\mathrm{TiO}_{2}$ nanoparticles by the sol-gel process.

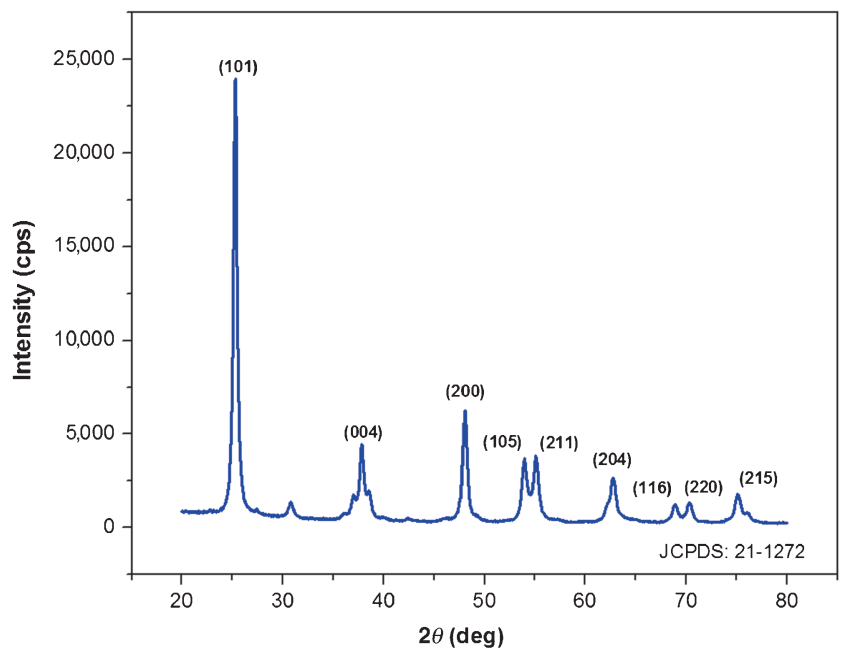

Figure 3. Powder X-ray pattern of sol-gel synthesized anatase phase $\mathrm{TiO}_{2}$ nanoparticles sintered at $450^{\circ} \mathrm{C}$.

shown in figure 5. The isotherm of sample reveals the stepwise adsorption and desorption branch of type IV curve, indicating the presence of mesoporous material having a three-dimensional (3D) intersection according to the IUPAC classification. A hysteresis loop with a stepwise adsorption and desorption branch is observed at wide range of pressure $\left(P / P_{\mathrm{O}}\right)$. The BET surface area of $\mathrm{TiO}_{2}$ nanoparticles is $31.76 \mathrm{~m}^{2} \mathrm{~g}^{-1}$ as shown in figure $5 \mathrm{a}$. This result indicates that the synthesized material has wider mesoporous structure. To analyse pore size, the plots of the pore size distribution are investigated by desorption branch of the $\mathrm{BJH}$ method as shown in figure $5 \mathrm{~b}$. The average pore diameters of mesoporous $\mathrm{TiO}_{2}$ nanostructures are 7.1 and $9.3 \mathrm{~nm}$. This kind of bimodal porous structure can be useful for efficient electrolyte diffusion into the photoanode in DSSC.

\subsection{Morphological studies}

Figure 6 shows the FESEM and HRTEM images of mesoporous $\mathrm{TiO}_{2}$ calcined at $450^{\circ} \mathrm{C}$. The morphology of synthesized material is spherical in shape. Discernable pores are present at the surface of samples. The pore structure is observed at the space between the nanoparticles, indicating that the interparticle porosity is due to the mesoporosity. From the FESEM analyses, the mechanism for the formation of mesoporous $\mathrm{TiO}_{2}$ nanoparticles can be analysed. As 

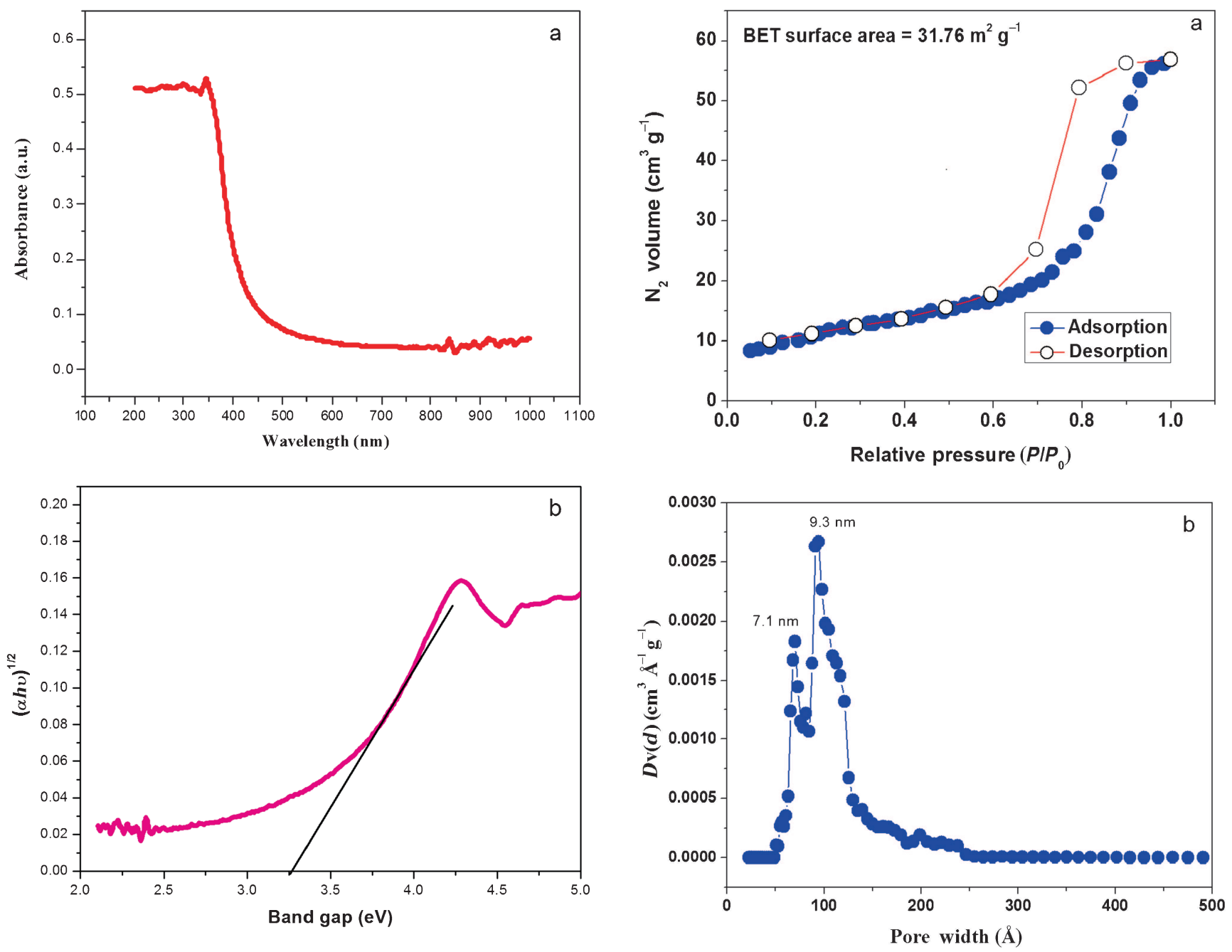

Figure 4. (a) Optical absorption (UV-Vis DRS) spectrum of anatase $\mathrm{TiO}_{2}$ nanoparticles and (b) plot of $(\alpha h v)^{1 / 2}$ vs. photon energy $(h v)$ for indirect transition.

can be seen from the FESEM images, the mesoporous structure probably arises from the aggregation of nanocrystallite $\mathrm{TiO}_{2}$ particles. When the titanium precursor was dissolved in ethanol, $\mathrm{TiO}_{2}$ nanoparticles can be formed via hydrolysis and condensation process. Further hydrolysis and condensation of titanium precursors lead to the growth of larger $\mathrm{TiO}_{2}$ nanoparticles, which are slowly aggregated to one another. As $\mathrm{TiO}_{2}$ nanoparticles are further aggregated, the $\mathrm{TiO}_{2}$ particles become microscopic particles, and finally form microspheres as shown in figure 6a and b. HRTEM images of sol-gel derived nanoparticles are shown in figure 6c. It confirms the clear spherical and homogeneous formation of nanoparticles. Selected area electron diffraction is shown in figure 6d which clearly indicates that $\mathrm{TiO}_{2}$ nanoparticles are highly crystallite in nature with anatase phase $\left(d_{(101)}=\right.$ $0.35 \mathrm{~nm}$ ). Figure $6 \mathrm{e}$ shows the individual particle of $\mathrm{TiO}_{2}$. As can be seen from the HRTEM images the average particle size is $\sim 20 \mathrm{~nm}$, which is in agreement with the crystallite size obtained from XRD. The elemental compositionof $\mathrm{TiO}_{2}$ nanparticles was verified with EDAX spectrum.

Figure 5. (a) Nitrogen adsorption and desorption isotherm analysis of $\mathrm{TiO}_{2}$ nanoparticles sintered at $450^{\circ} \mathrm{C}$ and (b) pore size distribution of $\mathrm{TiO}_{2}$ nanoparticles sintered at $450^{\circ} \mathrm{C}$.

Figure $6 \mathrm{f}$ shows the EDAX spectrum of sol-gel synthesized $\mathrm{TiO}_{2}$ nanoparticles.

\section{$3.5 I-V$ measurement}

The photovoltaic performance of solar cells (active area $0.25 \mathrm{~cm}^{2}$ ) was examined by using an Oriel Class AAA solar simulator equipped with AM $1.5 \mathrm{G}$ filter. The incident light intensity of the simulated light was calibrated to $100 \mathrm{~mW} \mathrm{~cm}{ }^{-2}$ by using a reference Si reference solar cell. The applied potential and cell current was measured using Keithley model digital source metre.

The overall efficiency of the DSSC can be obtained as product of the photocurrent density $\left(J_{\mathrm{sc}}\right)$, open-circuit voltage $\left(V_{\mathrm{oc}}\right)$, the fill factor $(\mathrm{FF})$ and the intensity of the incident light $(I)$

$$
\eta=V_{\mathrm{oc}} \times J_{\mathrm{sc}} \times \mathrm{FF} / I \text {. }
$$

The fill factor (FF) is derived from the $I-V$ curve

$$
\mathrm{FF}=I_{\mathrm{m}} \times V_{\mathrm{m}} / J_{\mathrm{sc}} \times V_{\mathrm{oc}},
$$




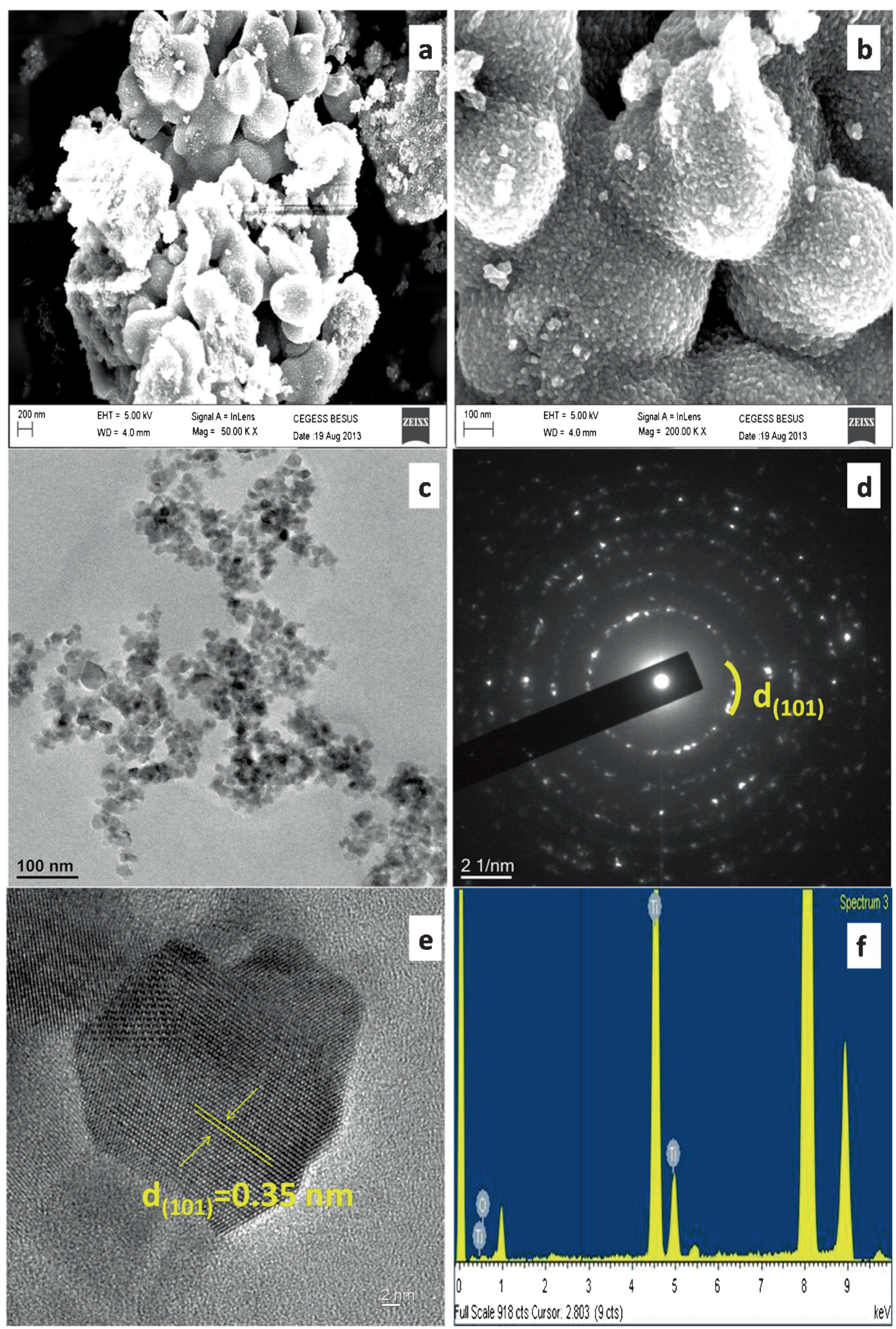

Figure 6. (a, b) FESEM image of porous $\mathrm{TiO}_{2}$ aggregates, (c) HRTEM image of $\mathrm{TiO}_{2}$ nanoparticles dispersed in ethanol, (d) SAED pattern of $\mathrm{TiO}_{2}$ nanoparticles, (e) HRTEM image of an anatase $\mathrm{TiO}_{2}$ nanoparticle with lattice fringes pattern of (101) plane and (f) EDX spectrum of $\mathrm{TiO}_{2}$ nanoparticles. 


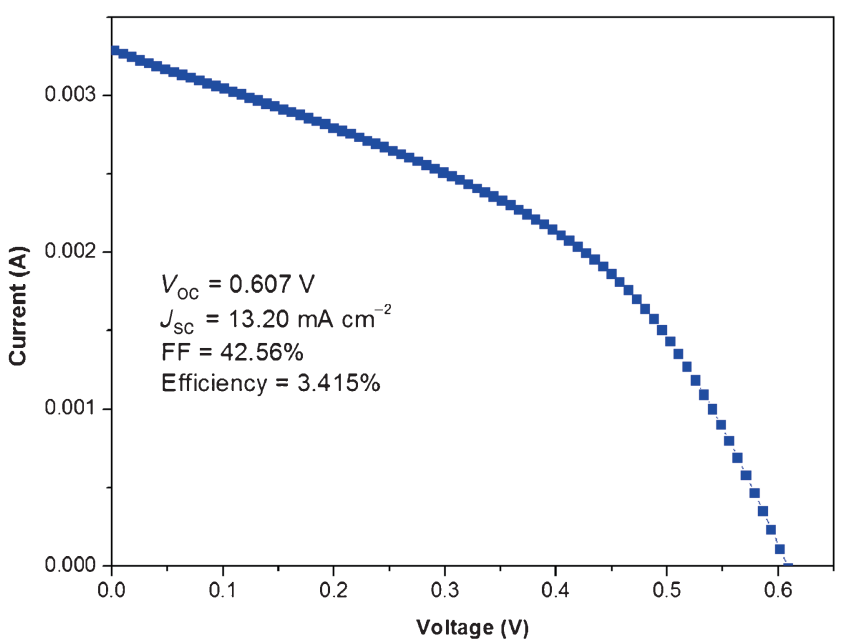

Figure 7. Photocurrent-voltage $(I-V)$ characteristics of dye sensitized solar cells.

where $V_{\mathrm{m}}$ is the maximum output voltage and $I_{\mathrm{m}}$ the maximum output current.

As depicted in figure 7, the conversion efficiency $(\eta)$ of the DSSCs was $3.415 \%$ with open-circuit voltage $\left(V_{\text {oc }}\right)$, short-circuit current $\left(J_{\mathrm{sc}}\right)$ and fill factor $(\mathrm{FF})$ of $0.607 \mathrm{~V}$, $13.206 \mathrm{~mA} \mathrm{~cm}{ }^{-2}$ and $42.56 \%$, respectively. This may be due to the effective light scattering and porous nature of the large size spherical nanoparticles. Kim et $a l^{12}$ reported, the maximum efficiency of the cell as $10 \%$ with the 776 $\mathrm{mV}$ based on spherical-shaped nanostructures. In the present case, the conversion efficiency and open-circuit voltage of the cell are lower than existing report, which may be due to the increased electron recombination rate in the interface of photoanode/electrolyte. ${ }^{16}$ However, this drawback can be solved by introducing the blocking layer on the photoanode and optimizing the thickness of the films.

\section{Conclusions}

The hierarchically structured anatase $\mathrm{TiO}_{2}$ nanoparticles were successfully synthesized by the sol-gel method without adding any surfactant. The powder X-ray studies show that synthesized materials are highly crystallite with anatase phase. The UV-Vis DRS spectrum shows that $\mathrm{TiO}_{2}$ nanoparticles absorption occurred at UV region. The band gap was evaluated to be $3.2 \mathrm{eV}$. The type IV isotherm shows mesoporous nature of the $\mathrm{TiO}_{2}$ nanoparticles. The BET isotherm shows the surface area of the nanoparticles as $31.76 \mathrm{~m}^{2} \mathrm{~g}^{-1}$. The pore sizes are 7.1 and $9.3 \mathrm{~nm}$ (bimodallike pores), which are evaluated from the BJH method. The morphological result shows that the synthesized particles are spherical in shape. The mesoporous order of spherically shaped sol-gel synthesized $\mathrm{TiO}_{2}$ nanoparticles reached $3.415 \%$ conversion efficiency. Finally, we claim that the spherical shape and bimodal-like pores of the $\mathrm{TiO}_{2}$ nanostructures can be used as a photoanode in DSSCs.

\section{Acknowledgements}

We express gratitude to Prof. A. K. Barua, Emeritus Professor, IIEST, Howrah, West Bengal, for useful discussion. We are grateful to Prof. D. Sahaya Sajan, PSN College of Engineering and Technology Tirunelveli, for carrying out the characterization measurements.

\section{References}

1. Fujishima A and Honda K 1972 Nature 23837

2. Grzmil B, Glen M, Kic B, Lubkowski K 2011 Ind. Eng. Chem. Res. 506535

3. Buchalska M, Kras G, Oszajca M, Łasocha W and Macyk W 2010 J. Photochem. Photobiol. A: Chem. 213158

4. Newman M D, Stotland M and Ellis J I 2009 J. Am. Acad. Dermatol. 61685

5. Zallen R and Moret M P 2006 Solid State Commun. 137154

6. Braun J H, Baidins A and Marganski R E 1992 Prog. Org. Coat. 20105

7. Yang P, Zhao D, Margolese D I, Chmelka B F and Stucky G D 1988 Nature 396152

8. Tian B, Liu X, Tu B, Yu C, Fan J, Wnang L, Xie S, Stucky G D and Zhao D 2003 Nat. Mater. 2159

9. Regan B O and Gratzel M 1991 Nature 353737

10. Nakade S, Saito Kubo Y W, Kitamura T, Wada Y and Yanagida S 2003 J. Phys. Chem. B 1078607

11. Martinson A B F, Hamann T W, Pellin M J and Hupp J T 2008 Chem. Eur. J. 144458

12. Kim Y J, Lee M H, Kim H J, Lim G, Choi Y S, Park N G, Kim $\mathrm{K}$ and Lee W I 2009 Adv. Mater. 213668

13. Deanna C H, Alexander G A and Kimberly A G 2003 J. Phys. Chem. B 1074545

14. Xu J, Li L, Yan Y, Wang H, Fu X and Li G 2008 J. Colloid Interface Sci. 31829

15. Zhao Y, Li C, Liu X, Gu F, Jiang H, Shao W, Zhang L and He Y 2007 Mater. Lett. 6179

16. Yong D, Li'e M, Li T, Yanmei M, Linhua H, Ling J, Zhaoqian L, Changneng Z, Bing Z, Jianxi Y and Songyuan D 2014 Nano: Brief Rep. Rev. 91440007 